7. Reprod. Fert. (1973) 34, 165-166

\title{
ENZYME COMPOSITION OF BUFFALO SEMINAL PLASMA
}

\author{
R. A. S. CHAUHAN AND R. K. SRIVASTAVA \\ Department of Biochemistry, \\ College of Veterinary Science and Animal Husbandry, \\ Fabalpur (M.P.), India
}

(Received 1st Fanuary 1973)

The preservation quality of buffalo semen is poor. The possibility that the cause is inherent in the enzyme system of the spermatozoa and seminal plasma has not so far been systematically studied. There are a few reports on acid and alkaline phosphatase (Eapen, Shrivastava \& RazaNasir, 1946; Roy, Pandey \& Rawat, 1960; Sengupta, Misra \& Roy, 1963; Misra, Singh \& Tomar, 1969), but no reports appear to be available on the normal activity of glutamicoxaloacetic transaminase (GOT), glutamic-pyruvic transaminase (GPT), lactic dehydrogenase (LDH) and aldolase in buffalo seminal plasma. Most of the enzymes, the activities of which have been estimated in seminal plasma, are also to be found in spermatozoa and there is a considerable possibility of 'leakage' of some of the intracellular enzymes, e.g. LDH and GOT. We have attempted to study this problem in connection with the distribution of aldolase (Chauhan \& Srivastava, 1973). The present communication deals with the normal values of the enzymes quoted above in buffalo seminal plasma.

The semen samples were obtained from six buffalo bulls. The seminal plasma was obtained by centrifugation of semen at $7000 \mathrm{~g}$ at $4^{\circ} \mathrm{C}$ for $10 \mathrm{~min}$ in a refrigerated centrifuge. The time lapse between collection and assay of samples was not more than $1 \mathrm{hr}$.

Alkaline and acid phosphatase levels were measured by the method of Bodansky (1932) in order to be able to compare these levels with other comparable data for buffaloes expressed in the same units. The activities of GOT and GPT were estimated by the procedure outlined by Yatzidis (1960). Values for LDH and aldolase were measured by the methods of Berger \& Broida (1969) and Sibley \& Lehninger (1971), respectively.

The normal activity levels of the enzymes in buffalo seminal plasma are presented in Table 1. The activities of acid and alkaline phosphatase were comparable to those reported by other workers. Lactic dehydrogenase activity was similar to that reported for bull seminal plasma (Stallcup \& Hayden, 1960; Roussel \& Stallcup, 1965a). Aldolase activity was less than that in bull seminal plasma (Roussel, Beatty, Pinero \& Patrick, 1970). The values for transaminase could not be compared because the methods of estimation and units differed from those reported by other workers for bull seminal plasma. The GOT/GPT ratio of 5:1 in buffalo seminal plasma recorded in this study is 
much narrower than that $(42: 1)$ reported for bull seminal plasma by Flipse (1960) or that (19:1) reported by Roussel \& Stallcup (1965b). The values obtained by these authors suggest that GOT/GPT ratios in bull seminal plasma are highly variable.

Table 1. Levels of enzymatic constituents in buffalo seminal plasma

\begin{tabular}{l|r}
\hline \multicolumn{1}{c|}{ Enzymes } & Mean activity $\pm S . E$. \\
\hline Alkaline phosphatase (BU/100 ml) & $315 \cdot 31 \pm 22.66(54)$ \\
Acid phosphatase (BU/100 ml) & $312.50 \pm 24.04(54)$ \\
Glutamic-oxaloacetic transaminase (units*/ml) & $166.72 \pm 14.08(54)$ \\
Glutamic-pyruvic transaminase (units*/ml) & $34.56 \pm 4.57(46)$ \\
Lactic dehydrogenase (BBU/ml) & $1671.50 \pm 113.11(20)$ \\
Aldolase (SLU/ml) & $70.31 \pm 27.79(7)$ \\
\end{tabular}

The figures in parentheses indicate the numbers of samples from six buffalo bulls. BU $=$ Bodansky units; $B B U=$ Berger-Broida units; $S L U=$ SibleyLehninger units.

* One unit is the amount of activity of seminal plasma that results in the formation of $1 \mu \mathrm{g}$ of pyruvate.

The phosphatase showed a highly significant difference $(P<0 \cdot 01)$ between buffalo bulls. There were no significant variations between buffalo bulls in the case of transaminases and lactic dehydrogenase.

\section{REFERENGES}

Berger, L. \& Broida, D. (1969) Sigma Technical Bulletin, No. 500. Sigma Chemical Gompany, U.S.A. BoDansky, A. (1932) Phosphatase studies. I. Determination of inorganic phosphate. Beer's law and interfering substances in the Kuttner-Lichtenstein method. 7. biol. Chem. 99, 197.

Ghauhan, R. A. S. \& Srivastava, R. K. (1973) Enzyme distribution in intact and fractionated buffalo spermatozoa. Proc. natn. Acad. Sci. India, 42, 38 (Abstr.).

Eapen, K. J., Shrivastava, P. N. \& RazaNasir, M. M. (1946) Relationship between some seminal constituents in buffalo semen. Indian vet. $\mathcal{F} .41,284$.

FlIPSE, R. J. (1960) Metabolism of bovine semen. IX. Glutamic-oxaloacetic and glutamic-pyruvic transaminase activities. 7. Dairy Sci. 43, 773.

Misra, B. S., Singh, B. P. \& Tomar, N. S. (1969) Studies on biochemical attributes of buffalo semen collected at various intervals. Indian J. Dairy Sci. 22, 202.

Roussel, J. D., Beatty, J. F., Pinero, A. \& Patricx, T. E. (1970) Parallelism between bovine semen characteristics, freezability and activity of seminal plasma aldolase. J. Dairy Sci. 53, 660.

Roussel, J. D. \& Stallcup, O. T. (1965a) Activity of lactic dehydrogenase and its isozymes in bovine semen. F. Dairy Sci. 48, 1506.

Roussel, J. D. \& Stallcup, O. T. (1965b) Parallelism between semen characteristics and GOT and GPT activities. 7. Dairy Sci. 48, 1684.

Roy, A., Pandey, M. D. \& Rawat, J. S. (1960) Composition of bovine semen. Indian J. Dairy Sci. 13, 112.

Sengupta, B. P., MisRa, M. S. \& Roy, A. (1963) Climatic environment and reproductive behaviour of buffaloes. I. Effect of different seasons on various seminal attributes. Indian J. Dairy Sci. 16, 150.

Srbley, J. A. \& Lehninger, A. L. (1971) Sigma Technical Bulletin, No. 750. Sigma Chemical Company, U.S.A.

Stallcup, O. T. \& Hayden, J. S. (1960) Lactic dehydrogenase activity in bovine semen. 7. Dairy Sci. 43, 266.

YATzidis, H. (1960) Measurement of transaminases in serum. Nature, Lond. 186, 79. 